\title{
A arte urbana e seus possíveis entrelaçamen- tos: considerações sobre intervenções artísticas efêmeras
}

\author{
The urban art and its possible links: considerations \\ on the ephemeral artistic interventions
}

por Isadora Gonçalves de Azevedo

RESUMO

As cidades são tema de investigação sobre o qual artistas de distintas épocas se debruçaram e, no contexto contemporâneo, frequentemente se debruçam. Por meio deste artigo, propomos algumas reflexões acerca da arte urbana, de modo a problematizar possíveis entrelaçamentos entre esta e assuntos como a democratização da arte, as desigualdades sociais, as políticas de desenvolvimento urbano e a privatização do espaço público, que se vincula à crescente individualização e, por consequência, à diminuição das ações e pensamentos coletivos. Abordamos, ainda, algumas considerações sobre intervenções artísticas efêmeras no contexto latino americano por meio de iniciativas desenvolvidas em três diferentes realidades: uma brasileira, uma chilena e uma argentina. Frisamos a carência de referências brasileiras que tratem de coletivos artísticos no contexto latino americano. Destacamos, por fim, a necessidade de refletirmos sobre os usos atuais do espaço público ao abordarmos a inserção da arte nesses ambientes e reiteramos nossa crença de que a arte pública pode atuar como um dispositivo político contra-hegemônico.

Palavras-chave: arte urbana, democratização da arte, intervenções artísticas efêmeras.

\section{ABSTRACT}

Cities are research topic that a lot of artists from different times have focused, especially in the contemporary context. In this paper, we propose some reflections on urban art, in order to discuss possible entanglements between this and issues such as democratization of art, social inequality, urban development policies and the privatization of public space, which is linked to the growing individualization and consequently, to the decrease of collective actions and thoughts. We discuss also some considerations about ephemeral art interventions in Latin American context through initiatives developed in three different realities: one Brazilian, one Chilean and one Argentine. We stress the lack of Brazilian references that deal with artistic collectives in Latin American context. We emphasize, finally, the need to reflect on the current uses of public space as we discuss the inclusion of art in these environments and we stress our belief that public art can act as a political counter-hegemonic.

Keywords: Urban art. Democratization of art. Ephemeral art interventions. 


\section{Introdução}

Uma vez inserida no espaço público, a arte alcança um público amplo e heterogêneo, de modo a interferir na formação estética de sujeitos que não necessariamente frequentem instituições como museus, galerias e espaços culturais. Não obstante, o interesse de artistas pela apropriação da cidade como tema e/ou como suporte tem longa trajetória histórica, apresentando vasta produção nos dois últimos séculos.

Este artigo traz algumas reflexões acerca da arte urbana, de modo a problematizar os possiveis entrelaçamentos desta com assuntos como a democratização da arte, as desigualdades sociais, as políticas de desenvolvimento urbano e a privatização do espaço público. Desta maneira, divide-se em breves seções, de modo a abordar, respectivamente: a arte urbana e suas relações com a democratização da arte e com a sensibilização dos cidadãos frente aos problemas da cidade; alguns apontamentos sobre a possibilidade de a arte contribuir com políticas de desenvolvimento urbano que a valorizem; uma breve explanação acerca de algumas intervenções artísticas efêmeras no contexto latino americano, especificamente, no Brasil, no Chile e na Argentina; as últimas considerações sobre 0 que 0 trabalho se propõe a problematizar, sem ter como pretensão encerrar o assunto, mas estimular outras produções referentes à arte urbana.

Procuramos destacar, ao longo do texto, que a arte pública pode atuar como um dispositivo político contra-hegemônico e que ela não é dita pública apenas por estar nas ruas, praças, parques, etc., senão por propiciar o debate sobre os usos do espaço público, dos problemas da cidade e do acesso à arte.

\section{A Arte Urbana e a Democratização da Arte}

Fabris (2000) afirma que a cidade engloba uma complexa rede de articulações culturais, que interferem nas concepções de mundo dos sujeitos e a caracterizam como algo vivo, exposto ao desgaste, à transformação e mesmo è destruição. Nessa perspectiva, a cidade é um centro de poder político-administrativo, bem como econômico, militar, religioso, artístico e cultural. Ela possibilita aos artistas confrontar obras e ideias, inserindo suas produções num circuito peculiar. Nas palavras da autora,

É nela que a produção artístico-cultural encontra estímulo e canais de divulgação, que o confronto entre o presente e o passado se torna mais acirrado, gerando aquela mobilidade de signos e símbolos, que é a verdadeira essência da vida urbana e de seus produtos simbólicos. (FABRIS, 2000, p. 10)

0 fenômeno urbano tem sido um campo de estudo bastante requisitado para a arte (cf. SANTOS, 2008) e, na contemporaneidade, as cidades são um importante material para ela, como tema e como suporte (cf. FERREIRA, 2005). Contudo, apesar desta relação entre arte e cidade ser recorrente em diversos períodos, vale lembrar que a inserção 
daquela no cotidiano dos sujeitos, especificamente, em espaços às vezes considerados banais, não significa supor que ela se mescle à realidade e perca seu caráter ficcional. A inclusão de obras de arte em lugares comuns, pertencentes ao cotidiano, contribui com a sensibilização estética e artística de indivíduos que possivelmente não visitam espaços culturais por falta de acesso e/ou de oportunidades. Além disso, a crescente demanda de artistas que almejam produções ligadas à vida nas cidades nos permite inferir que as tensões resultantes das relações humanas estabelecidas, sobretudo, nas ruas, com seus vestígios de encontros e desencontros, seguem despertando reflexões que não findam.

Pallamin (2000) ressalta que a arte urbana é uma prática social que propicia a reflexão sobre as diversas possibilidades de apreensão do espaço urbano. Nela, as questões estéticas se relacionam com as sociais, as políticas e as culturais. Ela se incorpora a espaços que sofrem interdições, contradições, conflitos; interfere nas relações de poder sobre o espaço entre grupos sociais, bem como nas interpretações do cotidiano e da história dos lugares; tem potencial para causar efeito de choque de sentidos (estranhamento, questionamento). A obra de arte se insere na produção do espaço e pode atuar a favor de diferentes propostas de produção da cidade, sendo esta entendida como forma social e não como espaço físico.

Por outro lado, Santos (2008) alerta que o sistema capitalista tem delegado os espaços destinados à arte como lugares de entretenimento. Desta forma, pode ser que esses ambientes não contemplem com densidade questões pertinentes à própria arte. Assim, a arte urbana desempenha papel importante na requalificação do cotidiano da cidade, uma vez que existem diversos tipos de arte pública, como o site-especific, a intervenção, a apropriação e o grafite, e essas ações podem ser efêmeras ou permanentes (cf. CARTAX0, 2009).

Cabe ressaltar que tematizar a arte urbana engloba a reflexão sobre a cultura urbana, entendendo-a como o modo como os sujeitos se relacionam e criam os aspectos sociais, políticos, econômicos, religiosos, intelectuais e artísticos. Destaca-se que a cultura tem caráter ambíguo, pois,

Por um lado, a dimensão da cultura associa-se ao processo de diferenciação de grupos sociais, delineando suas identidades, legitimando-os. Por outro lado, abarca o modo como se dão as relações entre esses diferentes grupos, as quais, frequentemente, são rugosas, de caráter agonístico. (PALLAMIN, 2000, p. 25)

Essa ambiguidade ganha destaque na natureza política da cultura e nos projetos que se debruçam sobre ela. Nesse sentido, a cultura pode ser usada como instrumento de discriminação social e como reforço de processos econômicos.

Diversas pesquisas, contudo, buscam reconhecer as contribuições da cultura urbana e apoiam a promoção desta por meio de atividades artísticas e culturais. É possível afirmar, então, que a profusão de projetos nestas áreas atua no fortalecimento da identidade local dos lugares urbanos, da diversidade cultural, da inclusão de grupos excluídos, além da construção de novas imagens dos bairros de periferia e da melhoria 
da qualidade de vida (cf. LOSSAU, 2005).

Conforme Pallamin (2000), a arte urbana deve reconsiderar a noção de público da arte, pois não se trata de um público restrito como no caso de museus e galerias. Na cidade, o público se forma a partir de seus interesses e, caso uma obra não atenda a estes, pode ocorrer a sua "falência". Nesse sentido, reiteramos a ideia de que ao situar-se em contextos rotineiros a arte não perde sua autonomia frente à realidade e, ainda que dialogue com outras áreas de conhecimento, neste ou em outros lugares, importa que não nos esqueçamos de que ela, por si só, não é capaz de solucionar os problemas da vida urbana, ainda que contribua com mudanças nas concepções de mundo.

Santos (2008) afirma que, ao intervir nos espaços urbanos, os/as artistas procuram ampliar as possibilidades de acesso ao universo artístico, sem que isso se dê de forma passiva, senão a partir de processos investigativos inseridos no cotidiano dos sujeitos. Dessa maneira, acreditamos que a inserção da arte na cidade contribui com a sua democratização, assim como propicia o engajamento político dela frente às desigualdades sociais, aos conflitos entre diferentes grupos e a outras questões referentes ao discurso neoliberal, conforme veremos adiante. Apesar das atribuições positivas em relação à arte urbana ou pública, é fundamental discernirmos as diferentes iniciativas e os objetivos que estão por trás delas.

\section{Arte e as Políticas de Desenvolvimento Urbano}

Lossau (2005) afirma que diversos pesquisadores têm se debruçado sobre a forma como a cultura urbana se relaciona com as políticas de desenvolvimento urbano. As mudanças na estrutura econômica vêm acarretando no crescimento das cidades que, de maneira recorrente, têm buscado seu desenvolvimento interno para conquistarem mais recursos. Dessa maneira, as cidades disputam entre si por colocações que nem sempre dialogam com determinados aspectos desse desenvolvimento, deixando transparecer questões superficiais e camuflando as desigualdades sociais e demais problemas não solucionados. A autora menciona que essa disputa pode ser comparada a de empresas, que visam um desenvolvimento endógeno e pouco se voltam para os conflitos presentes ao seu redor.

Nesse contexto, a cultura e a arte urbana podem servir de instrumento para as políticas de desenvolvimento urbano, pois o capital cultural é transformado em capital político e econômico. A inserção da arte na cidade pode contribuir, então, para mascarar as polarizações de classe, de etnia, entre outras. Cabe, aqui, trazermos o conceito de territorialidade, que se refere à subjetivação em relação ao espaço; envolve condutas e sentimentos de pertencimento (individuais e coletivos), construção de identidade e relações simbólicas. Dentre as possíveis funções da territorialidade, podemos destacar a defesa, o controle, o estabelecimento de fronteiras e hierarquias (cf. PALLAMIN, 2000, p. 31).

As ações sociais exercidas sobre um lugar modificam os significados atribuídos a ele, pois estão vinculadas às possibilidades de integrá-lo à malha urbana por meio de va- 


\section{A arte urbana e seus possíveis entrelaçamentos: considerações sobre in- tervenções artísticas efêmeras}

lores econômicos, caracterizando-o ou não como um lugar que recebe investimentos. Ao pensarmos o lugar urbano, portanto, é fundamental discernirmos as utilizações de seus recursos, quem usufrui deles, as relações de poder que estão presentes, de modo a perceber os conflitos existentes entre os possíveis valores de uso de tais recursos e a manipulação sobre eles como valores de troca.

Assim, a valorização de determinados lugares sobre outros gera "economias" por um lado e "deseconomias" por outro. A vida nas cidades caracteriza-se por conflitos referentes à "socialização capitalista", que transfere os recursos da população para poucas pessoas e firmas. Como bem menciona Pallamin,

Essa capitalização do território urbano é sinônimo de modos de privatização excludente no uso de benfeitorias produzidas coletivamente, dentre as quais destacam-se os espaços públicos, que, em tese, seriam locais privilegiados na expressão de cidadania cultural e política.( PALLAMIN, 2000, p. 34)

Quanto aos projetos artísticos inseridos nesse contexto, há de se destacar, por outro lado, que nem todos os projetos são financiados pelo Estado. Existem projetos que recebem financiamento de empresas e os que são custeados pelos próprios artistas/propositores. Atentamos, pois, para a privatização e o encolhimento do espaço público em função de individualização e da propagação do discurso neoliberal (cf. BAUMAN, 2001).

Com relação a esse assunto, cabe destacar a maneira como Arendt (2010) descreve os domínios do público versus o privado e do social versus o político. Conforme a autora, a Era Moderna mesclou as esferas do privado (antes restrito ao lar) e do público (a vida na polis), nas quais o ser humano era entendido, respectivamente, como ser social e como ser político. Assim, apesar de relacionar-se com os sujeitos do lar, ele não era necessariamente um ser político. A vida na polis é que permitia ao/a homem/mulher adquirir tal caráter. Na modernidade, tais domínios se mesclaram e a subjetividade e a individualização adentraram a esfera pública, que vem perdendo força como um local de coletividade e de cidadania.

Nossa defesa é por projetos artísticos que caminhem numa direção oposta a esta, de forma que sejam entendidos como dispositivos políticos com vistas à democratização da arte e à interferência nas desigualdades sociais, de modo a atuar na luta por mudanças radicais. Interessa-nos compreender e defender, portanto, as possibilidades de a arte atuar, em especial, nos espaços públicos, como um instrumento de luta contra 0 discurso hegemônico. Nas palavras de Capasso,

Es en el espacio público donde tienen lugar manifestaciones políticas, sociales, culturales, instancias de participación social que dependen de la coyuntura histórica. A su vez, estas prácticas modifican y moldean el espacio público, lo conforman y lo definen. En este espacio público se producen entonces instancias de enunciación, las cuales pueden interpelar al orden de cosas hegemónico. (CAPASSO, 2011, p. 1)

Importa destacar que muitos artistas consideram a sociedade bastante fragmentada e 
desigual e que, mesmo inserida no espaço público, a arte não alcança a toda a população. Além disso, o modo como cada sujeito ou grupo social se apropria da produção artística é variado (cf. LOSSAU, 2009). Desta forma, a arte urbana não pode ser entendida, do ponto de vista dos artistas, como um instrumento preciso para o desenvolvimento urbano, no que diz respeito aos interesses do Estado e de empresas. As expectativas dos artistas e dos políticos, portanto, nem sempre convergem.

Levando em conta o que foi exposto até aqui, frisamos a necessidade de, ao pensarmos a inserção da arte no espaço público, refletirmos acerca dos usos atuais do espaço urbano e da maneira como os governos e as empresas se apropriam dela, encobrindo objetivos que nem sempre são os mesmos dos artistas. Acreditamos ser importante defender a ideia de que a arte na cidade é bastante pertinente frente a questões como o encolhimento e a privatização do espaço público, as desigualdades sociais, a fragmentação dos coletivos em função da individualização. Como já mencionamos, ela pode ser entendida como um meio para que novas concepções acerca do espaço urbano se consolidem e se fortaleçam.

\section{Algumas Considerações Sobre a Arte Efêmera}

Conforme Freyberger (2008), pensar a rua como espaço de debate é um bom fundamento para uma sociedade democrática. 0 espaço público é um lugar de trocas, de movimento contínuo. Nele, adquirimos informação e conhecimento acerca da vida e temas atuais. Boa parte das obras de arte inseridas nele caminha contra a direção da despolitização do espaço público, bem como contra a privatização dele. A autora ressalta o fato de ser cada vez mais comum nos depararmos com intervenções artísticas efêmeras, escultóricas e performativas e afirma que dentre as efêmeras, algumas se sobressaem por seu caráter político, por tocarem em feridas da sociedade, atuando com pertinência no debate sobre determinadas questões.

Nessa perspectiva, destacamos os trabalhos que o grupo Poro vem desenvolvendo no Brasil. 0 Poro é formado por uma dupla de artistas de Minas Gerais: Brígida Campbell e Marcelo Terça-Nada. Desde 2002, os artistas trabalham com intervenções efêmeras que buscam problematizar os problemas das cidades, atuando não apenas nos públicos, como também nos diversos meios de comunicação, em especial pela internet'.

De acordo com Carvalho (2011), as intervenções deste coletivo levam em conta quatro pontos fundamentais: 1) o trabalho colaborativo, que requer a interação do espectador; 2) a dimensão ética, que engloba a maneira como as pessoas são afetadas pelos trabalhos; 3 ) a dimensão política, que busca combater a ordem capitalista mundial, o individualismo, com vistas a outras possibilidades de perceber e de habitar o mundo contemporâneo; 4) as virtualidades, referentes ao que é possível ser feito, mas não o foi. Por meio de faixas, cartazes, panfletos, dentre outras formas de intervenção, 0 grupo se apropria de temas do cotidiano e, dessa forma, nem sempre os trabalhos são entendidos como artísticos. Em alguns casos, eles são considerados um acaso poético.

1 Para maiores informações, consulte: 〈http://poro.redezero.org.> 
Dentre as diversas intervenções artísticas do coletivo, destacamos, aqui: 1) o cartaz Compartilhe o espaço urbano [1], disponibilizado no site oficial do Poro, bem como em redes sociais e outros sites, para que qualquer pessoa possa imprimi-lo, distribuí-lo e usá-lo; 2) os Aquários suspensos [2], referentes à inserção de imagens de peixes nas luminárias de espaços públicos.

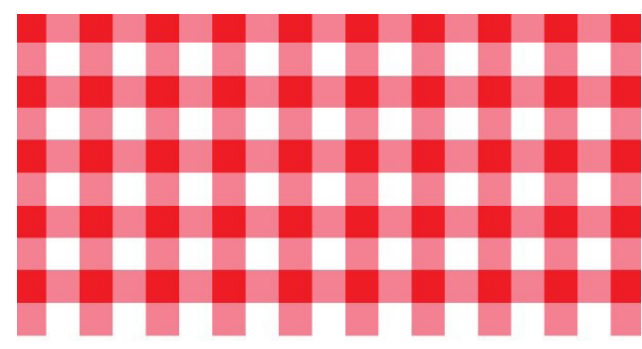

COMPARTILHE O ESPAC̣O PÚBLICO

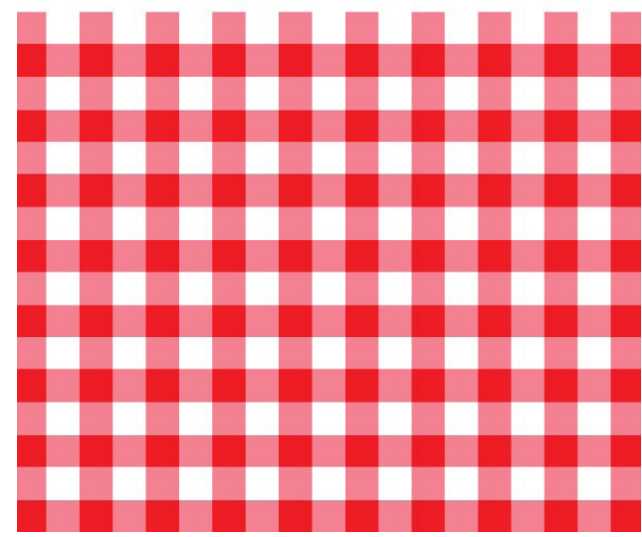

FIGURA 1: Compartilhe o espaço público. Poro, 2011.

Fonte: 〈http://poro.redezero.org/cartazes/cartaz-compartilhe-o-espaco-publico/〉

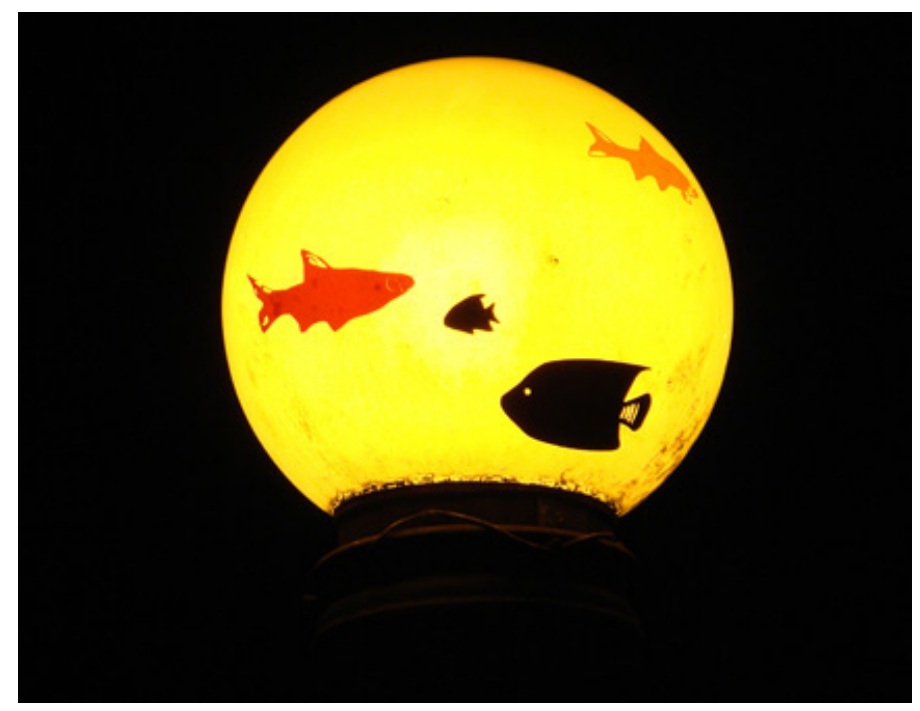

FIGURA 2: Aquários suspensos. Poro, 2007.

Fonte: 〈http://poro.redezero.org/biblioteca/resenha-poro-um-grande-deslocamento-revista-concinnitasuerj/> 


\title{
A arte urbana e seus possíveis entrelaçamentos: considerações sobre in- tervenções artísticas efêmeras
}

Ao que nos parece, o primeiro trabalho faz uma analogia à opção de compartilhamento de imagens e textos disponibilizados pelas redes sociais em diversos países e regiões. Estabelece-se, assim, uma relação de contradição entre a reunião de pessoas nos ambientes virtuais e as consequentes trocas que ali ocorrem versus o encolhimento do espaço público e o aparente desinteresse por assuntos coletivos não virtuais. A imagem, que é compartilhada via rede, atenta para o tempo dedicado às relações a distância e aquele destinado aos encontros nos espaços públicos.

Da mesma maneira, ao despertar a atenção, por meio de uma intervenção nas luminárias, em pessoas que transitam pelos mesmos lugares e, talvez, não reparem nos detalhes destes espaços, o grupo incita pequenas mudanças de postura no cotidiano de inúmeros sujeitos. Acreditamos que trabalhos como estes são capazes de impactar, ainda que de forma sutil, o cotidiano dos sujeitos que, em meio à experiência da velocidade $^{2}$, pouco desenvolvem sua percepção espacial. Como bem menciona Freyberger,

\begin{abstract}
La buena noticia está en las calles: Si miramos con atención las intervenciones de arte efímero, identificamos una fuerza motriz en común, que esta en la búsqueda de hacer algo, de decir algo, de fomentar encuentros, reflexiones, mínimos cambios de postura. Un arte político. Un arte que tiene una dimensión curativa del social. La trascendencia político-social de estas intervenciones efímeras, tiene mucho que ver con su planteamiento desde la empatía, el enfoque positivo y abierto a la participación de la comunidad y que son un contrapunto a la dimensión opaca de la sociedad: El individualismo, el miedo a los miedos de la sociedad, al conflicto y a la tragedia social entre otros. ( FREYBERGER, 2008, p. 1)
\end{abstract}

A autora ressalta, ainda, a capacidade de alguns artistas de reunir forças no espaço público, ampliando a relação entre a obra e o lugar para os meios de comunicação, atingindo diversas regiões do mundo. Freyberger retoma a arte efêmera dos anos 1970 e afirma que ela vem ganhando consistência, em especial a partir de 1990, quando 0 termo arte pública passou a contemplar novos significados:

El primero, la construcción de espacios públicos a partir de trabajos de equipos compuestos de arquitectos, diseñadores, artistas, psicólogos ambientales entre otros. Y el segundo, los eventos de arte efímero: intervenciones, performances, artes interactivos y participativos que muchas veces también son elaborados por colectivos o equipos multidisciplinares. (FREYBERGER, 2008, p. 1)

2 Sennett (2003) traz a experiência da velocidade como um fator determinante para a compreensão de como essas interações ocorrem no cotidiano contemporâneo. A facilidade para se deslocar de um espaço para o outro, tanto dentro da cidade quanto de um país ao outro, transforma os espaços em locais de passagem. Os espaços urbanos apresentam vias cada vez mais bem sinalizadas, com trajetos que facilitam o deslocamento entre as partes da cidade. 0 motorista adquire a imagem de que os espaços funcionam como um corredor a ser atravessado, deixando de estabelecer contatos mais próximos com o ambiente que o cerca. Dessa maneira, prestar atenção nos diversos lugares da cidade torna-se desnecessário: perceber o espaço através da visão é suficiente, os demais sentidos podem ser descartados, e o viajante é então comparado ao telespectador. Sennett (2003) define os dois como corpos passivos, visto que ambos se apropriam da tecnologia para interagir com o espaço e as pessoas, 0 que torna esse contato menos arriscado e mais cômodo. 


\section{A arte urbana e seus possíveis entrelaçamentos: considerações sobre in- tervenções artísticas efêmeras}

Esse tipo de arte não é considerada pública meramente por estar nas ruas, mas por posibilitar que as manifestações artísticas não partam apenas dos detentores de poder, isto é, a população também ganha força de expressão com tais iniciativas. 0 crescimento dessas ações evidencia o compromisso de artistas com questões sociais e, por ser uma prática política não institucionalizada, sua repercussão pode ser mais eficaz. Conforme a autora, transformar a realidade é uma das potencialidades da arte. Tal força pode ser usada pelo poder político para o embelezamento e a especulação do espaço urbano, assim como pode ser assunto para cidadãos organizados num movimiento de luta contra o poder político. Ambas as formas podem ocorrer, inclusive, de modo concomitante.

Em 2012, no Chile, a cidade de Santiago abrigou a primeira edição do festival de intervenção urbana Hecho en casa, na qual mais de quinze artistas e coletivos criaram instalações que foram desenvolvidas especificamente em função do evento. Hecho en casa propôs reflexões sobre a cidade como um espaço de comunicação, no qual a arte participa de forma ativa do discurso público e do que diz respeito ao âmbito urbano. Temos na sequência [3 e 4] imagens de alguns dos diversos trabalhos que compuseram o evento.

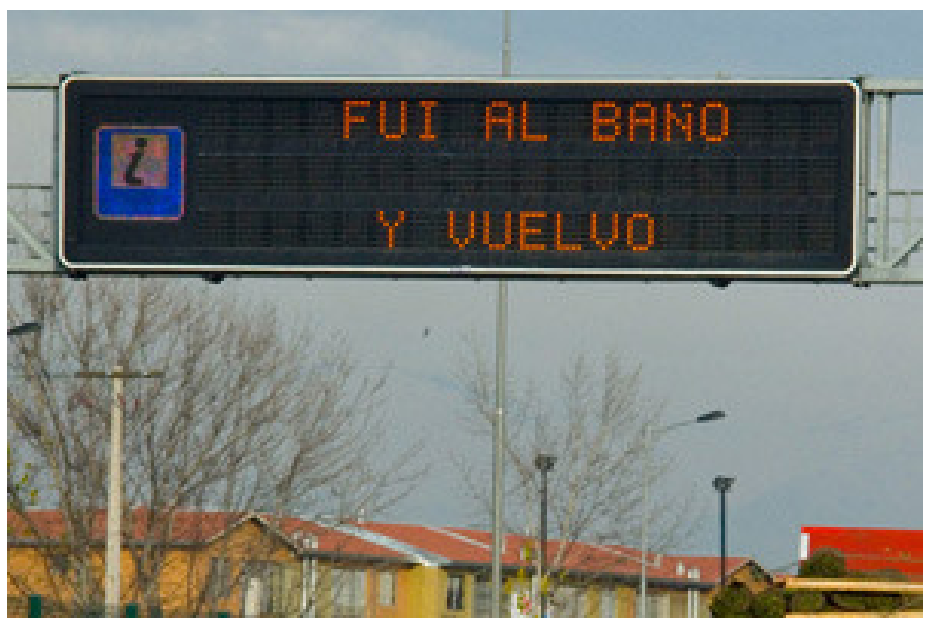

FIGURA 3: Soy autopista é uma intervenção simples nos letreiros luminosos da Avenida Central com mensagens divertidas. Grupo Grifo, Festival Hecho em casa, 2012.

Fonte: 〈http://www.hechoencasa.cl/events/72> 


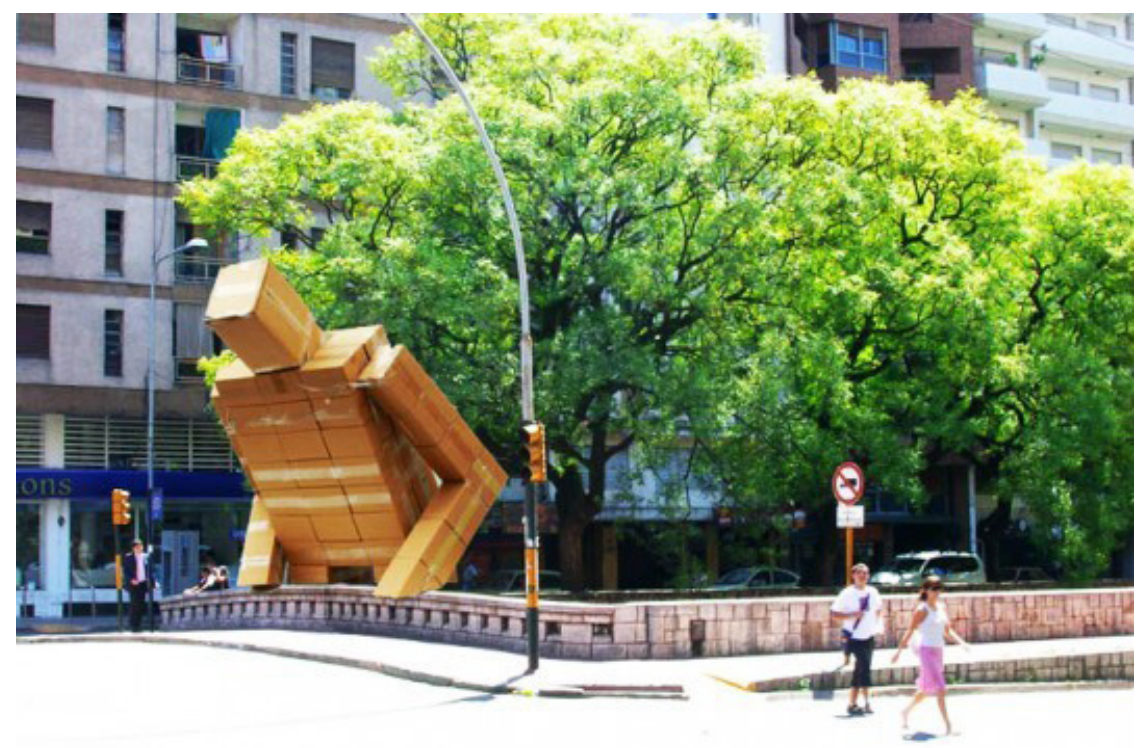

FIGURA 4: Construção de um robô de nove metros de altura e meio tonelada de peso, confeccionado com caixas de papelão. Uma vez desmontado, os papelões serão doados a uma organização de catadores de papelão para que sejam reciclados. PABLO CURUTCHET, Festival Hecho em casa, 2012. Fonte: 〈http://www.hechoencasa.cl/events/95>.

Mais uma vez, podemos perceber o deslocamento de objetos do cotidiano de maneira a gerar estranhamento e surpresa nas pessoas que transitam por tais lugares. A mudança no texto do letreiro de uma avenida, substituido por um recado íntimo, que remete ao espaço privado - o lar -, traz à tona reflexões sobre regras e condutas da vida social.

0 tamanho do boneco de papelão, por outro lado, pode nos despertar para a escala humana em meio aos prédios e demais construções dos ambientes urbanos, além de questões como o deslocamento de cada indivíduo por espaços próximos e distantes. Não obstante, o lugar em que se encontra o boneco também nos permite refletir sobre partes das ruas às quais não nos atemos. Seria aquele lugar um rio, um canal de esgoto, dentre outras opções? Com que frequência observamos estas peculiaridades e o porquê de elas estarem ali?

Em 2013, a segunda edição do evento trouxe trabalhos de novos artistas para os espaços públicos de Santiago e, como podemos ver na figura 5, muitas das intervenções têm se apropriado do que os lugares disponibilizam como material a ser explorado. 0 grafite realizado, iniciativa do Coletivo CENIT, composto por artistas e arquitetos, inicia no canto inferior direito da imagem, com uma criança segurando um carretel cuja linha acompanha o fio de luz que segue em direção ao alto de um prédio, situado no canto superior esquerdo, onde consta o fim do grafite - uma pipa. Eis uma alternativa de dar destaque a elementos que compõem tal ambiente e passam despercebidos a muitos transeuntes: atribuir-Ihes um significado. 


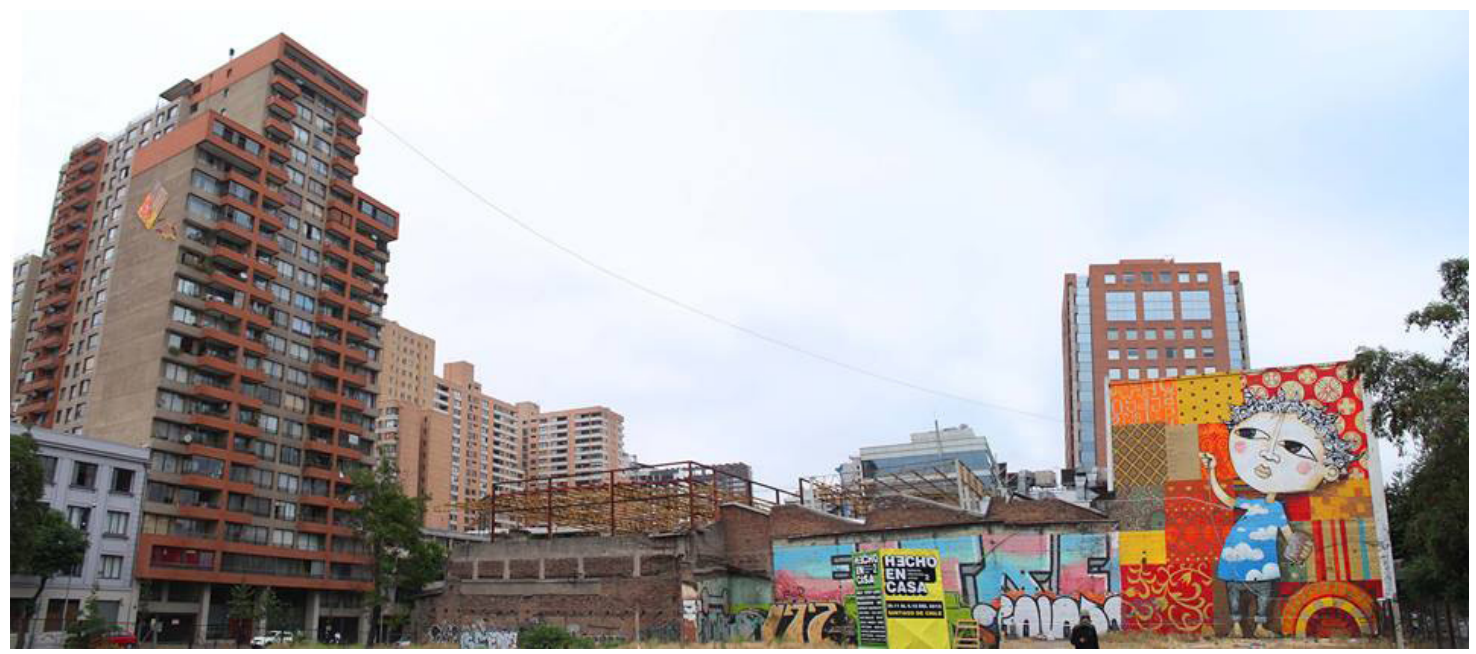

FICURA 5: Grafite sem título. Coletivo CENIT, Festival Hecho em casa, 2013. Fonte: < http://www.hechoencasa.cl/artists/colectivo-cenit>.

Acreditamos que festivais como o Hecho em casa tornar-se-ão cada vez mais comuns e é importante atentarmo-nos para as intenções que podem estar por trás de financiadores desse tipo de evento, conforme vimos nas seções anteriores, para que discursos hegemônicos não se apropriem dessas iniciativas e deslegitimem-nas. Segundo Alonso,

\begin{abstract}
La negación del marco institucional interpretativo determina la necesidad de construir un entorno de metacomunicación que califique la intervención o la acción, en vistas a evitar su completa asimilación en el contexto con la consiguiente pérdida de su eficacia conceptual, estética o reflexiva. Estos aspectos metacomunicativos son difíciles de generar, lo que muchas veces pone en peligro el destino y los objetivos de estas intervenciones. (ALONSO, 2000, p. 3)
\end{abstract}

Já na década de 1990, com a expansão do discurso neoliberal na América Latina, alguns grupos se organizaram e realizaram intervenções no espaço público em função da privatização de diversas instituições. É o caso do grupo argentino Costuras Urbanas, que realizou intervenções como Privatizado [6], em 1997, e Vote lo que quiera [7], em 1999. Na primeira, onze artistas, posicionados lado a lado, formavam a palavra privatizado e permaneciam durante um minuto em frente a edifícios, ruas, instituições. Na última, os artistas instalaram uma urna numa das ruas centrais de Córdoba e convidavam os transeuntes para votar naquilo que desejassem. Os votos, reunidos, foram expostos no Centro Cultural General Paz ${ }^{3}$.

3 Cf. 〈http://www.vivodito.org.ar〉. 
A arte urbana e seus possíveis entrelaçamentos: considerações sobre intervenções artísticas efêmeras

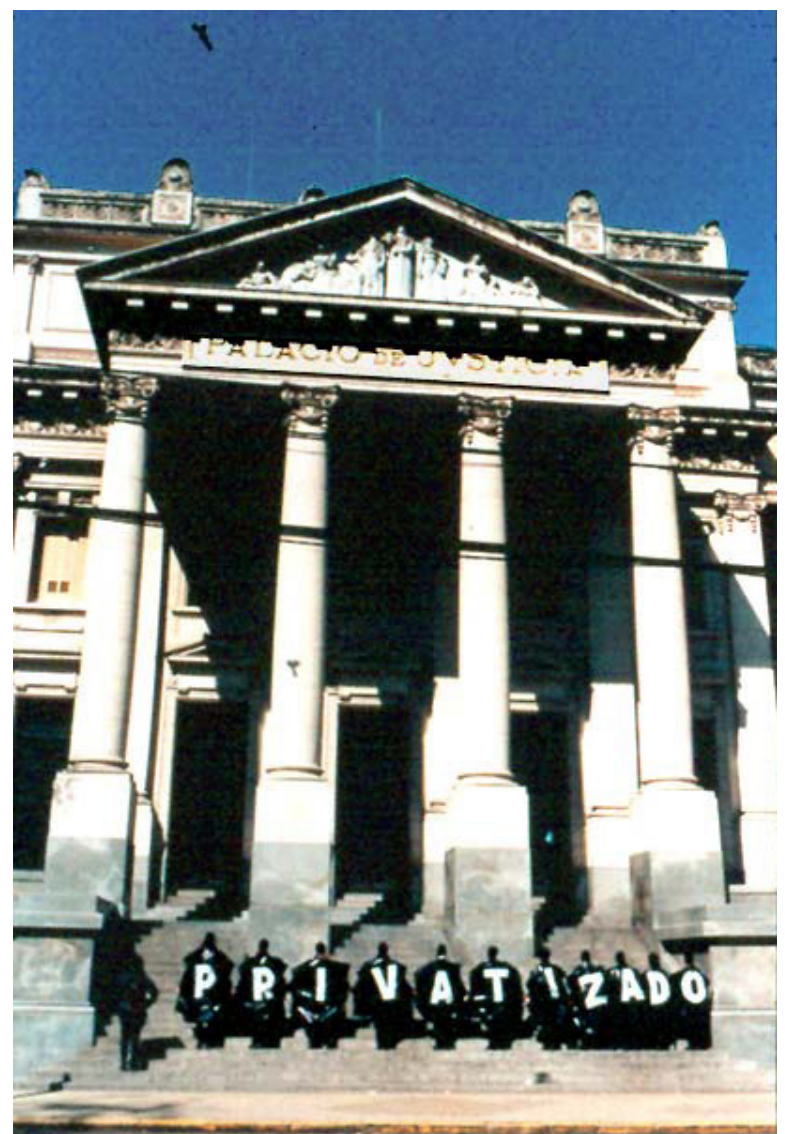

FIGURA 6: Privatizado. Grupo Costuras Urbanas. Córdoba, Argentina, 1997. Fonte: ALONSO, 2000, p. 1.

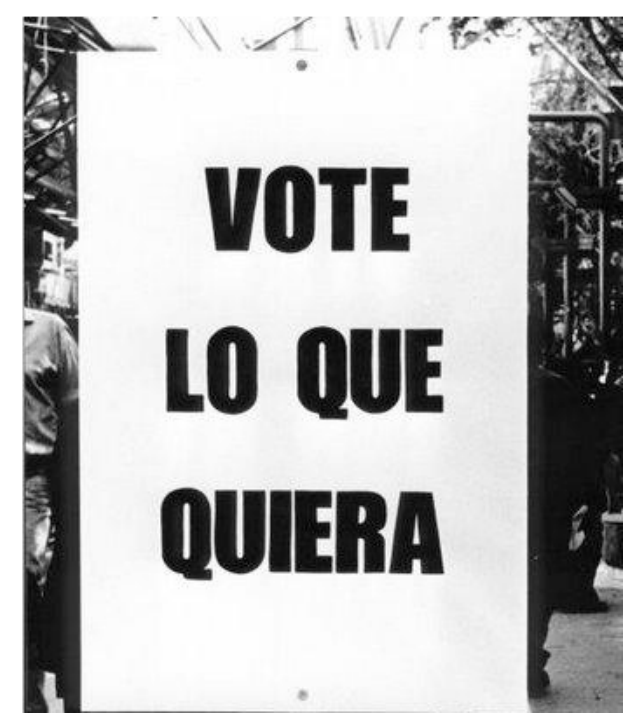

FIGURA 7: Vote loque quiera. Grupo Costuras Urbanas. Córdoba, Argentina, 1999. Fonte: 〈http://www.vivodito.org.ar/node/127〉.

Os trabalhos apresentados aqui ilustram parte do que vem se desenvolvendo em países latino americanos nas últimas décadas e que pouco tem sido mencionado nas pesquisas acadêmicas. Ao que parece, ainda existe uma lacuna entre algumas produções artísticas no espaço urbano e as pesquisas desenvolvidas no âmbito universitário. Por 


\section{A arte urbana e seus possíveis entrelaçamentos: considerações sobre in- tervenções artísticas efêmeras}

outro lado, acreditamos que esse também é um campo que tende a crescer com o passar dos anos.

\section{Considerações Finais}

Propusemo-nos, neste artigo, a trazer algumas considerações acerca da arte urbana e, especificamente, de ações efêmeras realizadas no espaço público. Abordamos o potencial da arte como dispositivo político na luta contra o discurso hegemônico e na sensibilização dos cidadãos frente aos problemas da cidade. Destacamos, também, possíveis vínculos entre alguns projetos artísticos e culturais e as políticas de desenvolvimento urbano que estão mais voltadas para interesses particulares do que para os da coletividade.

Apresentamos alguns trabalhos de caráter efêmero no âmbito latino americano, tema que ressaltamos, aqui, ter escassa produção acadêmica no cenário nacional. Frisamos, pois, a necessidade do desenvolvimento de mais pesquisas que se debrucem sobre 0 contexto regional em que estamos inseridos. Não obstante, acreditamos que a universidade, por ser um local privilegiado pela construção de conhecimento, tem potencial para aproximar-se mais de iniciativas referentes aos usos do espaço público, as quais nem sempre são registradas, historicizadas ou mesmo problematizadas. Assim, não apenas pesquisas, como também parcerias podem e devem ser firmadas no tocante da arte pública. 


\section{Referências Bibliográficas}

$>$ ALONSO, Rodrigo. La cuidad-escenario: itinerarios de La performance pública y La intervención urbana. Jornadas de Teoría y Crítica. La Habana: Bienal de La Habana: 2000.

> ARENDT, Hannah. A condição humana. 11. ed. rev. Rio de Janeiro: Forense Universitária: 2010.

> BAUMAN, Zygmunt. Modernidade líquida. Rio de Janeiro: J. Zahar: 2001.

$>$ CAPASSO, Veronica Cecilia. Apropiaciones y reapropiaciones del espacio de la ciudad. Un análisis de intervenciones artístico-políticas contemporáneas en la transformación del imaginario sobre lo público. Question 1.32: 2011.

$>$ CARTAX0, Zalinda. Arte nos espaços públicos: a cidade como realidade. 0 Percevejo Online, Rio de Janeiro, v.1, nć 1, 2009. Disponível em: 〈http://www.seer.unirio.br/index. php/opercevejoonline/article/view/431/381>. Acesso em 13 de fevereiro de 2013.

> CARVALHO, Isabel. Poro: um grande deslocamento. Revista Coincinnitas. UERJ, vol. 1, nć18, 2011. Disponível em: 〈http://www.concinnitas.uerj.br/〉. Acesso em 24 de fevereiro de 2013.

> COSTURAS URBANAS. Disponível em: 〈http://costurasurbanascba.blogspot.com.br/〉. Acesso em: 17 de fevereiro de 2013.

> FABRIS, Annateresa. Fragmentos urbanos: representações culturais. São Paulo: Studio Nobel: 2000.

> FERREIRA, Lua Maia. 0 espaço urbano como suporte para a arte. Simpósio Nacional sobre Geografia, Percepção e Cognição do Meio Ambiente. Paraná, 2005. Disponível em: 〈http://geografiahumanista.files.wordpress.com/2009/11/luana_maia.pdf〉. Acesso em: 13 de fevereiro de 2013.

$>$ FESTIVAL HECHO EM CASA. Disponível em: 〈http://www.hechoencasa.cl/intervenciones〉. Acesso em 20 de fevereiro de 2013.

> FREYBERGER, Gisele. La dimensión pública Del arte contemporâneo. El arte necesario: intervenciones artísticas efímeras em espacios públicos. Diez años de cambios en el Mundo, en la Geografía y en las Ciencias Sociales, 1999-2008. Actas del X Coloquio Internacional de Geocrítica. Universidad de Barcelona, 2008. Disponível em: 〈http://www. ub.edu/geocrit/-xcol/202.htm>. Acesso em 19 de fevereiro de 2013.

> LOSSAU, Julia. Arte no espaço público: Sobre as relações entre as perspectivas artísticas e as expectativas das políticas de desenvolvimento urbano. GeoTextos, América do Norte, 5, ago. 2009. Disponivel em: 〈http://www.portalseer.ufba.br/index.php/geotextos/ article/view/3568/2633>. Acesso em: 12 de Fevereiro de 2013.

> PALLAMIN, Vera M. Arte urbana: São Paulo: Região Central (1945-1998) obras de caráter temporário e permanente. São Paulo: ANNABLUME, FAPESP: 2000.

> PORO. Disponível em: 〈http://poro.redezero.org/〉. Acesso em 21 de fevereiro de 2013. 
A arte urbana e seus possíveis entrelaçamentos: considerações sobre intervenções artísticas efêmeras

> SANTOS, Maria Ivone dos. A observação de um lugar urbano como ação da arte. In: RAMOS, Célia Maria Antonacci (Org.). Camelódromo Cultural: IV Colóquio Poéticas do urbano. Florianópolis: Bernuncia: 2008.

> SENNETT, Richard. Carne e pedra: o corpo e a cidade na civilização ocidental. 3. ed. Rio de Janeiro: Record: 2003

> VIVO DITO. Disponível em: 〈http://www.vivodito.org.ar〉. Acesso em 20 de fevereiro de 2013.

Isadora Gonçalves de Azevedo, Mestranda em Artes Visuais - Programa de Pós-Graduação em Artes Visuais da Universidade do Estado de Santa Catarina.

isadoracga@gmail.com 